\title{
Histopathological differentiation and incidence of soft tissue tumors: study of 140 cases
}

\author{
Patel Y. M. ${ }^{1}$, Tandel H. K. ${ }^{2}$ \\ ${ }^{1}$ Dr. Yogita kumari Manilal Patel, ${ }^{2}$ Dr. Hetal kumari Kishor bhai Tandel, Tutor; both authors are affiliated with \\ Department of Pathology, GMERS Medical College, Valsad, Gujarat, India.
}

Address for Correspondence: Dr. Hetal kumari Kishor bhai Tandel, Email:hetaltandel022@gmail.com

\begin{abstract}
Background: The incidence of soft tissue tumors, especially the frequency of benign tumors relative to malignant ones, is never determined accurately. The fact that many benign tumors, such as lipomas and hemangiomas, do not undergo biopsy makes direct application of data from most hospital series invalid for the general population. Histologic grade represents the most important Prognostic factor for all soft tissue sarcomas, strongly associated with the advent of metastasis and patients survival. Objectives: the objective of the study was to find occurrence of soft tissue tumor and analyse various type and subtypes of soft tissue tumors. Methodology: a prospective study carried out at tertiary care teaching hospital. The operated specimens or biopsy material of soft tissue tumors received were studied in detailed by department of Histopathology. Histological diagnosis was achieved either by performing incisional or trucut needle biopsy and/or reviewing the slides when patient underwent biopsy elsewhere. Observations: The incidence were high in the age group of 31 to 40 years ( 36 cases, 25\%), followed by 21 to 30 years (24 Cases, 17.1\%) and 41 to 50(21 Cases, $15 \%$ ) years. However the malignant tumor incidence was high at age of 51 to 60 years of age. Region wise involvement shows soft tissue tumors were found in head and neck region $(29.2 \%)$, followed by genital region (25.7\%) and upper limb (15.8\%). Type wise distribution was lipomatous $(28.5 \%)$, followed by smooth muscle tumor $(21.5 \%)$, peripheral nerve sheath tumor (17.9\%), Tumor of blood and lymph vessels (17.1\%), Conclusion: benign soft tissue tumor are much common than the malignant tumors. Among benign tumors lipomatous tumors are common followed by smooth muscle tumor and other tumors.
\end{abstract}

Key words: Soft tissue tumor, Histopatological examination, Lipomatous tumor

\section{Introduction}

Soft tissue tumors are defined as mesenchymal proliferations which occur in the extraskeletal nonepithelial tissues of the body, excluding the viscera, coverings of brain and lymphoreticular system. The annual incidence of soft tissue tumor is 1.4 per 100000 population. Soft tissue tumors are the fourth most common malignancy in children, after hematopoietic neoplasm, neural tumor and wilmstumor [1]. The incidence of soft tissue tumors, especially the frequency of benign tumors relative to malignant ones, is nearly impossible to determine accurately. Benign soft tissue tumors outnumber malignant tumors by a wide margin. The fact that many benign tumors, such as lipomas and

Manuscript received: $10^{\text {th }}$ August 2017

Reviewed: $20^{\text {th }}$ August 2017

Author Corrected: $29^{\text {th }}$ August 2017

Accepted for Publication: $4^{\text {th }}$ September 2017 hemangiomas, do not undergo biopsy makes direct application of data from most hospital series invalid for the general population. Histologic grade represents the most important Prognostic factor for all soft tissue sarcomas, strongly associated with the advent of metastasis and patients survival [1,2].

The use of ancillary techniques like immunohistochemistry, electron microscopy flow cytometry and cytogenetics, has increased insight into the tumor biology and has provided tools for greater diagnostic accuracy. Yet the foundation of these newer techniques rests upon the histologic diagnosis made on light microscopic evaluation of hematoxylin and eosin stained sections and use of special stains. It is critical to recognize immunohistochemistry as an adjunctive 
technique, which does not supersede or replace the traditional morphologic diagnosis [3]. Soft tissue masses present a challenge to the pathologist because of their extremely varied morphology and biologic behaviour [4].

So, the objective of the study was to find occurrence of soft tissue tumor and analyse various type and subtypes of soft tissue tumors.

\section{Materials and Methodology:}

Study design and setting:It was a prospective study carried out at B J Medical College and Civil Hospital from September 2014 to July 2015. Scientific and Human Research Ethical committee permission was taken before starting of the study.

Inclusion and Exclusion criteria:Participants were explained about the purpose and objectives of the study before enrolling in the study.

The participants who gave the written consent were included in the study.
The operated specimens or biopsy material of soft tissue tumors received during the study period from surgery department. And they were studied in detailed by department of Histopathology. Only mesenchymal lesions originating in soft tissue were included in the study. Intra-abdominal and retroperitoneal lesions were also included when the lesions were not thought to originate in bowel or abdominal viscera. Lesions arising in the chest and abdominal walls were also included. Age and sex incidence, site of lesion, clinical features, gross and microscopic appearance were carefully studied as per the proforma. Histological diagnosis was achieved either by performing incisional or trucut needle biopsy and/or reviewing the slides when patient underwent biopsy elsewhere. Routinely in our institute Hematoxylin and Eosin staining is done. Special stain like Phosphotungstic acid haematoxylin (PTAH), trichrome stain, reticulin stain, alcian blue stain, and Periodic Acid Schiff (PAS) reaction were also used in diagnosis of histological types and subtypes whenever required.

Statistical analysis done using Microsoft excel sheets.

\section{Result}

Over a period of one year and 3 months total 140 cases of soft tissue tumor could be included in the study. Among them majority of tumor $[125(89 \%)]$ were benign in nature. Whereas $9 \%$ of tumor were malignant and $2 \%$ were intermediate in nature [Table 1]

In this study, age of study subjects were ranging from 0 to 70 years. Peak incidence of the tumors were in the age group of 31 to 40 years (36 cases, 25\%), followed by 21 to 30 years (24 Cases, 17.1\%) and 41 to 50(21 Cases, 15\%) years.

Incidences of tumors were found decreased in both the extreme of age group which are in the 0 to 10 years (11 Cases, $7.9 \%$ ) and 61 to 70 years (11 Cases, 7.9\%). [Table 2] However the malignant tumorincidence increase as the advances of the age. And it shows highest at age of 51 to 60 years of age [ 5 cases $(3.57 \%)$ ].

Gender wise distribution shows out of total 140, nearly 58\% were male and $42 \%$ were female with Male: Female ratio was 1.37:1. [Table 3] Nature wise distribution shows that benign, intermediate and malignant tumors were similarly distributed in male and female.

Table-1: Distribution of tumors according to nature.

\begin{tabular}{|c|c|c|}
\hline Category & Frequency & Percentage \\
\hline Benign & 125 & $89.3 \%$ \\
\hline Intermediate & 2 & $1.4 \%$ \\
\hline Malignant & 13 & $9.3 \%$ \\
\hline Total & $\mathbf{1 4 0}$ & $\mathbf{1 0 0} \%$ \\
\hline
\end{tabular}


Table- 2: Age wise distribution of nature of tumors.

\begin{tabular}{|c|c|c|c|c|}
\hline \multirow{2}{*}{$\begin{array}{c}\text { Age (In completed } \\
\text { years) }\end{array}$} & \multicolumn{3}{|c|}{ Category } & \multirow{2}{*}{ Total } \\
\cline { 2 - 4 } & Benign & Intermediate & Malignant & $11(7.86 \%)$ \\
\hline $0-10$ & $9(6.43 \%)$ & $0(0.00 \%)$ & $2(1.43 \%)$ & $19(13.57 \%)$ \\
\hline $11-20$ & $18(12.86 \%)$ & $0(0.00 \%)$ & $1(0.71 \%)$ & $24(17.14 \%)$ \\
\hline $21-30$ & $24(17.14 \%)$ & $0(0.00 \%)$ & $0(0.00 \%)$ & $36(25.71 \%)$ \\
\hline $31-40$ & $33(23.57 \%)$ & $1(0.71 \%)$ & $2(1.43 \%)$ & $21(15.00 \%)$ \\
\hline $41-50$ & $19(13.57 \%)$ & $0(0.00 \%)$ & $2(1.43 \%)$ & $18(12.86 \%)$ \\
\hline $51-60$ & $12(8.57 \%)$ & $1(0.71 \%)$ & $5(3.57 \%)$ & $11(7.86 \%)$ \\
\hline $61-70$ & $10(7.14 \%)$ & $0(0.00 \%)$ & $1(0.71 \%)$ & $\mathbf{1 4 0}(\mathbf{1 0 0} \%)$ \\
\hline Total & $\mathbf{1 2 5}(\mathbf{8 9 . 2 9} \%)$ & $\mathbf{2 ( 1 . 4 2 \% )}$ & $\mathbf{1 3}(\mathbf{9 . 2 9} \%)$ & \\
\hline
\end{tabular}

Table- 3: Gender wise distribution of nature of tumors.

\begin{tabular}{|c|c|c|c|c|}
\hline \multirow{2}{*}{ Gender } & \multicolumn{3}{|c|}{ Category } & \multirow{2}{*}{ Total } \\
\cline { 2 - 5 } & Benign & Intermediate & Malignant & $81(57.86 \%)$ \\
\hline Male & $73(52.14 \%)$ & $1(0.71 \%)$ & $7(5.00 \%)$ & $59(42.14 \%)$ \\
\hline Female & $52(37.14 \%)$ & $1(0.71 \%)$ & $6(4.29 \%)$ & $140(100 \%)$ \\
\hline Total & $125(89.29 \%)$ & $2(1.42 \%)$ & $13(9.29 \%)$ & $1.37: 1$ \\
\hline M:F ratio & $1.4: 1$ & $1: 1$ & $1.17: 1$ & \\
\hline
\end{tabular}

Table- 4: Gender wise and category wise distribution of histopathological type of tumor

\begin{tabular}{|c|c|c|c|c|c|c|c|}
\hline \multirow[t]{2}{*}{ Type of tumor } & \multicolumn{2}{|c|}{ Gender } & \multirow[t]{2}{*}{ Total } & \multicolumn{3}{|c|}{ Category } & \multirow[t]{2}{*}{ Total } \\
\hline & Male & Female & & Benign & Intermediate & Malignant & \\
\hline Lipomatous Tumor & 15 & 25 & 40 & 38 & 0 & 2 & 40 \\
\hline Smooth muscle tumor & 30 & 0 & 30 & 30 & 0 & 0 & 30 \\
\hline Peripheral Nerve sheath tumor & 14 & 11 & 25 & 25 & 0 & 0 & 25 \\
\hline Tumor of blood and lymph vessel & 5 & 19 & 24 & 22 & 2 & 0 & 24 \\
\hline Fibroblastic and myofibroblastic tumor & 6 & 5 & 11 & 7 & 0 & 4 & 11 \\
\hline Stromal tumor & 2 & 2 & 4 & 0 & 0 & 4 & 4 \\
\hline Perivascular Tumors & 0 & 2 & 2 & 2 & 0 & 0 & 2 \\
\hline Skeletal Muscle Tumors & 1 & 1 & 2 & 0 & 0 & 2 & 2 \\
\hline $\begin{array}{c}\text { Extra skeletal Osseous And } \\
\text { Cartilaginous } \\
\text { Tumors }\end{array}$ & 2 & 0 & 2 & 1 & 0 & 1 & 2 \\
\hline Total & 75 & 65 & 140 & 125 & 2 & 13 & 140 \\
\hline
\end{tabular}

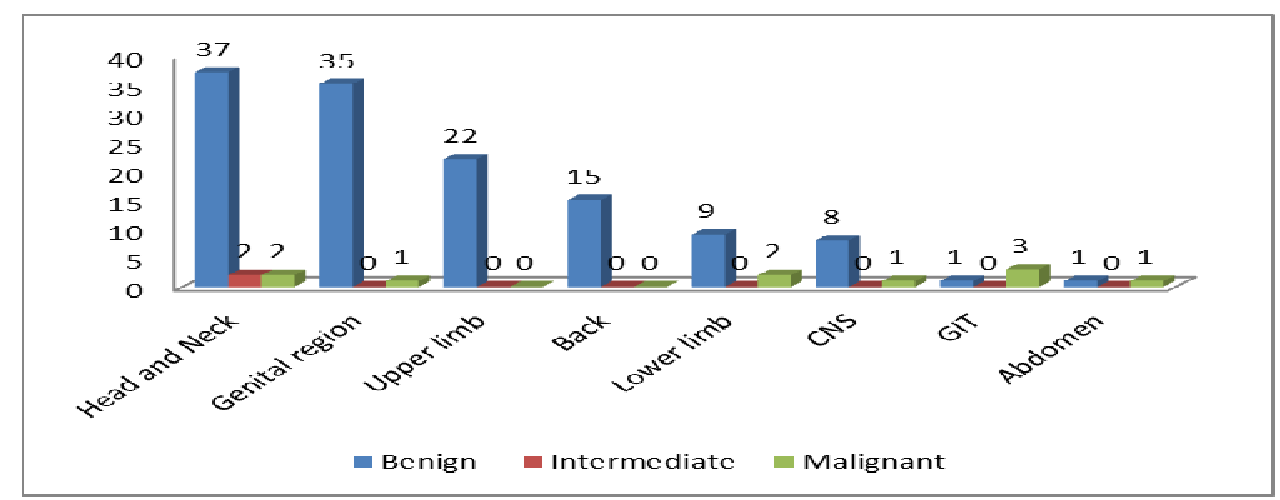

Figure-1: Anatomical location of soft tissue tumors according to category 
In this study, around one third of the soft tissue tumors were found in head and neck region (29.2\%), followed by genital region (25.7\%) and upper limb (15.8\%). Soft tissue tumors were also found in other regions like lower limb, Back, CNS, GIT, Abdomen but in lower incidence [figure 1]. Benign lesions commonly found in Head and neck region, followed by genital region, upper limb and back. Malignant soft tissue lesions werecommonly seen in GIT followed by upper limb and head and neck.

Majority of the soft tissue tumors were lipomatous (28.5\%) in nature, followed by smooth muscle tumor (21.5\%), peripheral nerve sheath tumor (17.9\%), Tumor of blood and lymph vessels (17.1\%), Fibroblastic/ myofibroblastictumors $(7.9 \%)$, rest were from the other types of the soft tissue tumor. Among benign tumors lipomatous tumor and leiomyomas were the most common tumors. While other benign tumors were tumor from peripheral nerve sheath and from blood and lymph vessels. The common malignant tumors were stromal tumors and Fibroblastic and myofibroblastictumors. Two patient found with intermediate tumor had epithelioid hemangioendothelioma. [Table 4]

\section{Discussion}

Soft tissue can be defined as non-epithelial, extraskeletal tissues of the body exclusive of the reticuloendothelial system, glia and supporting tissues of various parenchymal organs. It is represented by the voluntary muscles, fat and fibrous tissue, along with the vessels serving these tissues. By convention, it also includes peripheral nervous system. Total 140 cases of soft tissue tumors were studied over a period of one year in this study.

The incidence of benign tumor in present study was $89 \%$ while in the study by Mirza et al (2005) [57/5] the incidence rate of Benign tumor was $82 \%$. The incidence rate of malignant tumors was less (10.7\%) in present study as compared to the study by Mirza et al (18\%) [5]. The difference found in the result is might be due to recent newer advance technique of diagnosis, tumor can be detected at very early stage. In the study of Mirza et al the ratio of Benign : Malignant is 4.70 : 1 , where as in present study the ratio found $8.3: 1$, which is higher as compared to previous study, as due to newer technique of diagnosis the tumor can be detected in benign stage [5].

Average age of occurrence of benign tumor in the study by Mirza et al was 29.2 years, which is similar to the present study (32.1 years). Whereas the average age of incidence of malignant tumor found highly increased in present study which is 55.6 years as compared to previous study of Mirza et al it was 37.8 years. The ratio of $\mathrm{M}$ : $\mathrm{F}$ found of benign and malignant is similar in the study of Mirza et al and in the present study [5].

In the present study adipose tissue tumors constituted, the commonest soft tissue tumor accounting for $50 \%$ of all soft tissue tumors. The male to female ratio of 1.34 :
1 showing a male predominance. These findings are in good correlation with most of the study reported in literature of Mirza et al(2005) [5], Kransdorf et al 1995 $[6,7]$ and Enzinger and Weiss [8,9,10]. In the study of Mirza et al, there were 3 cases of liposarcomas accounting for $12.5 \%$ of all malignant soft tissue tumors. Whereas in present study there were 2 cases of liposarcomas accounting for $13.3 \%$ of all malignant soft tissue tumors.

These finding are found similar with the studies conducted by Kransdorf et al [6]. In the literature of Weiss SW regarding soft tissue sarcomas, liposarcomas comprised $21 \%$ of all sarcomas. So the finding of this study is comparable to the above mentioned studies. Fibrous tumors comprised fifth most common tumor among all soft tissue tumors in present study. Fibrous tumors were diagnosed in 11 cases that comprised $7.9 \%$ of all soft tissue tumors. The sex and site of fibrous tumors in the present study are comparable with those studies of the Mirza et al (2005) and of Kransdorf's study. Hemangiomas were second most common among benign tumors constituting 20 cases accounting for $17.69 \%$ of all benign soft tissue tumors.

These findings are also very similar with the studies reported by Kransdorf. The average age of hemangiomas in this study was 31.16 years, which is little higher as compared to studies reported Mirza et al and Kransdorf. This is because; in this study the age range varied from 10 to 80 years. [11]. The sex and site distribution were similar to the literature given in Enzinger and Weiss (2001). [10] In the present study benign-malignant ratio is 8.3: 1 while in the study of Mirza et al, there were 113 benign tumors and 24 malignant tumors with a benignmalignant ratio of 
4.70:1. This is due to the fact that many benign tumors such as lipoma and hemangioma do not undergo biopsy as compared to sarcoma, which come to medical attention quite early [11]. However, in Kransdorf study the incidence of malignant tumorswere high which might be because of thereffered cases from peripheral centres [7]. In conclusion, in the present study benign tumors comprised $89 \%$ and malignant tumor comprised $10.7 \%$ among all tumors and benign tumors are common in occurred in second and third decade of life. In the present study majority of malignant soft tissue tumors occurred in fifth decade of life.

Funding: Nil, Conflict of interest: None initiated, Permission from IRB: Yes

\section{References}

1. Joyner CJ, Triffitt J, Puddle B, et al: Development of a monoclonal antibody to the aP2 protein to identify adipocyte precursors in tumors of adipose differentiation. Pathol Res Pract 1999;195:461.

2. Nnodim JO. Development of adipose tissues. Anat Rec 1987; 219:331.

3. Brooks JJ, Perosio PM: Adipose tissue. Histology for pathologists, 2nd edn. Philadelphia: LippincottRaven; 1997:167.

4. Ross R. The smooth muscle cell. II. Growth of smooth muscle in culture and formation of elastic fibers. J Cell Biol. 1971 Jul;50(1):172-86.
5. Baig MA. Histological study of soft tissue tumor (Three Year Study). International Journal of Science and Research (IJSR) 2005: 1039 - 49.

6. Kransdorf MJ. Malignant soft-tissue tumors in a large referral population: distribution of diagnoses by age, sex, and location. AJR Am J Roentgenol. 1995 Jan;164 (1):129-34.

7. Kransdorf MJ. Benign soft-tissue tumors in a large referral population: distribution of specific diagnoses by age, sex, and location. AJR Am J Roentgenol. 1995 Feb; 164(2):395-402.

8. Weiss SW, Enzinger FM. Myxoid variant of malignant fibrous histiocytoma. Cancer. 1977 Apr; 39 (4): 1672-85.

9. Weiss SW, Goldblum JR. Benign lipomatous tumors. Chapter-16 In: Enzinger and Weiss's Soft Tissue Tumors. 4th Edition, St. Louis: Mosby, 2001: 571- 639 .

10. Weiss SW, Goldblum JR. Liposarcoma. Ch Weiss SW, Goldblum JR. Liposarcoma. Chapter-17 In: Enzinger and Weiss's Soft Tissue Tumors. 4th Edition, St. Louis: Mosby, 2001: 641-693.

11. Ross R. The smooth muscle cell. II. Growth of smooth muscle in culture and formation of elastic fibers. J Cell Biol. 1971 Jul;50(1):172-86.

\section{How to cite this article?}

Patel Y. M, Tandel H. K. Histopathological differentiation and incidence of soft tissue tumors: study of 140 cases. Trop J Path Micro 2017;3(3):335-339.doi: 10.17511/jopm.2017.i3.19. 